\title{
Flora das cangas da Serra dos Carajás, Pará, Brasil: Vochysiaceae
}

Flora of the cangas of Serra dos Carajás, Pará, Brazil: Vochysiaceae

Gustavo Hiroaki Shimizu ${ }^{1,3}$ \& Deise Josely Pereira Gonçalves ${ }^{2}$

\begin{abstract}
Resumo
Este estudo apresenta as espécies de Vochysiaceae que ocorrem em vegetação de canga na Serra dos Carajás, no estado do Pará, Brasil, incluindo descrições morfológicas, ilustrações e comentários. Foram registradas quatro espécies: Callisthene microphylla, Qualea multiflora, Q. parviflora e Vochysia haenkeana.
\end{abstract}

Palavras-chave: Amazônia, Callisthene, Qualea, taxonomia, Vochysia.

\begin{abstract}
This study presents the species of Vochysiaceae that occur in canga vegetation of Serra dos Carajás, in the Pará state, Brazil, including morphological descriptions, illustrations, and comments. Four species were recorded: Callisthene microphylla, Qualea multiflora, Q. parviflora and Vochysia haenkeana.
\end{abstract}

Key words: Amazon, Callisthene, Qualea, taxonomy, Vochysia.

\section{Vochysiaceae}

Vochysiaceae A.St.-Hil. é composta por oito gêneros e cerca de 240 espécies (Shimizu \& Yamamoto 2012), apresentando distribuição anfiatlântica, mas predominantemente neotropical (Marcano-Berti 2005; Senterre \& Obiang 2005). São geralmente árvores, de filotaxia oposta ou verticilada, cálice calcarado, corola com número reduzido de pétalas e um único estame fértil (Kawasaki 2007). No Brasil são registradas 162 espécies, em seis gêneros (Flora do Brasil 2020). Na Serra dos Carajás ocorrem oito espécies, sendo quatro delas em áreas de canga. As demais espécies, ocorrentes em floresta de terra firme, são: Erisma uncinatum Warm., Qualea dinizii Ducke, Vochysia maxima Ducke e V. obidensis (Huber ex Ducke) Ducke.

\section{Chave de identificação dos gêneros de Vochysiaceae das cangas da Serra dos Carajás}

1. Folhas opostas, dispostas em râmulos filomórficos; fruto maduro com exocarpo facilmente separável do restante do pericarpo; sementes circularmente aladas 1. Callisthene

1'. Folhas opostas ou verticiladas, não dispostas em râmulos filomórficos; fruto maduro com pericarpo íntegro; sementes unilateralmente aladas.

2. Estípulas associadas a glândulas crateriformes; flores com uma pétala

2. Qualea

2'. Estípulas não associadas a glândulas crateriformes; flores com três pétalas 3. Vochysia

\section{Callisthene Mart.}

Callisthene compreende 11 espécies e ocorre principalmente no Planalto Central brasileiro em áreas de vegetação savânica, campestre e florestal, mas não é considerado endêmico devido a registros de ocorrência no Paraguai e na Bolívia (Stafleu 1952; Martins 1981, 1988; França 1996; Bueno et al. 2000; Flora do Brasil 2020). Análises moleculares indicam proximidade filogenética entre Callisthene, Qualea Mart. e Ruizterania Marc.-Berti (Litt 1999; Shimizu et al., em preparação). Apesar da frequente sobreposição de características morfológicas diagnósticas a nível específico e infraespecífico, Callisthene pode ser facilmente reconhecido por ser o único gênero da família que apresenta folhas dispostas em râmulos filomórficos (semelhantes a uma folha pinada),

\footnotetext{
${ }^{1}$ Universidade Estadual de Campinas, Inst. Biologia, Depto. Biologia Vegetal, C.P. 6109, 13083-970, Campinas, SP, Brasil.

${ }^{2}$ The University of Texas at Austin, Department of Integrative Biology, 2415 Speedway, 78712, Austin, TX, USA.

${ }^{3}$ Autor para correspondência: gustavoshimizu@gmail.com
} 
fruto maduro com exocarpo facilmente separável do restante do pericarpo e sementes circularmente aladas (Shimizu \& Gonçalves 2015).

1.1. Callisthene microphylla Warm. in Mart. \& Eichler, Fl. bras. 13(2): 28, t. 3, fig. 1. 1875.

Figs. 1a-b; 2a-b

Arbustos ou árvores, 1-9 m alt. Ramos de casca não descamante em placas. Râmulos filomórficos. Gemas peruladas globosas. Folhas de filotaxia oposta; estípulas caducas, não associadas a glândulas; pecíolos ca. 0,1 cm compr.; lâminas foliares $0,7-1,4 \times 0,3-0,6 \mathrm{~cm}$, orbiculares na região proximal dos râmulos a oblongas, até lanceoladas na região distal dos râmulos, tricomas presentes apenas na nervura primária da face abaxial; ápice retuso, obtuso, truncado ou agudo, geralmente mucronado, base arredondada, margem plana, ciliada. Flores isoladas axilares; pedúnculos ca. $0,2 \mathrm{~cm}$ compr.; botões florais $3-6 \times 1,5-2 \mathrm{~mm}$, ápice agudo; cálcar 1-2 mm compr., reto; sépala calcarada 7-8 mm compr.; lobos do cálice não calcarados 2-4 mm compr.; corola com 1 pétala, branca com mácula amarela na região central, 7-8 $\times$ 5-8 mm, glabra; estame ca. $4 \mathrm{~mm}$ compr., antera ca. $1 \mathrm{~mm}$ compr., glabra, filete ca. $3 \mathrm{~mm}$ compr.; estaminódios ausentes; ovário ca. $1 \times 1 \mathrm{~mm}$, glabro ou pubescente; estilete $4-5 \mathrm{~mm}$ compr., glabro; estigma terminal. Cápsula globosa a elipsoide, superfície não descamante.

Material selecionado: Canaã dos Carajás, S11D, $6^{\circ} 23^{\prime} 58^{\prime}$ 'S, 50²0'51'”, 771 m, 06.XII.2007, fr., N.F.O. Mota et al. 1064 (BHCB, MG); Serra da Bocaina, 6¹9'44”'S, 4955'56”'W, 725 m, 12.XII.2012, fr., A.J. Arruda et al. 1304 (BHCB); Serra do Tarzan, 6² 19'47'S, 50 07'52”'W, 731 m, 1.IX.2015, fl., R.M. Harley et al. 57342 (MG, UEC); Parauapebas, Serra Norte, N1, $6^{\circ} 18^{\prime} 00^{\prime \prime}$, 50 50'16'59'W, 7.XII.2013, fr., R.S. Santos et al. 166 (MG); N3, 28.X.1985, fl., R. Secco \& O. Cardoso 639 (MG); N4, 606'32”S, 50¹'48”'W, 3.IX.2015, fl.,
A. Gil et al. 513 (MG, UEC); N5, 26.I.2002, fr., S.M. Faria et al. 2317 (RB); N6, 606'43”S, 50'11'02”'W, 704 m, 24.II.2016, fr., R.M. Harley et al. 57390 (MG); N8, 6009'46”S, 5009'50"W, 695 m, 27.III.2015, fr., $A$. Cardoso et al. 1953 (MG).

Apresenta râmulos filomórficos, semelhantes a uma folha pinada, e fruto maduro com exocarpo facilmente separável do restante do pericarpo. Em Carajás foi registrada com flores em julho, setembro e outubro, sendo uma das espécies mais vistosas no período da seca, e com frutos de dezembro a maio.

Espécie endêmica do Brasil, presente em cerrados, campos e carrascos (Stafleu 1952; Martins 1981). No Brasil ocorre nos estados da Bahia, Ceará, Goiás, Maranhão, Minas Gerais, Pará, Piauí e Tocantins (Gonçalves et al. 2017). Na Serra dos Carajás foi coletada na Serra Norte: N1, N3, N4, N5, N6 e N8, e na Serra Sul: S11D, além das Serras da Bocaina e Tarzan, em formações rupestres e capões florestais sobre canga.

\section{Qualea Mart.}

O gênero Qualea inclui cerca de 50 espécies, distribuídas nas Américas Central e do Sul (MarcanoBerti 2005; Shimizu et al. 2016). No Brasil, 37 espécies ocorrem em florestas tropicais e em vegetação savânica (Flora do Brasil 2020). Callisthene, Qualea e Ruizterania formam um clado (Litt 1999), cujas relações intergenéricas estão em estudo (Shimizu et al., em preparação). Qualea e Callisthene apresentam flores com uma única pétala, mas Callisthene geralmente apresenta flores isoladas e axilares e Qualea apresenta inflorescências ou sinflorescências tirsoides terminais ou subterminais (Gonçalves et al. 2017). Além disso, Qualea distingue-se de Callisthene e de Vochysia por apresentar glândulas axilares associadas às estípulas e frutos com pericarpo íntegro e valvas livres após a deiscência (Gonçalves et al. 2017).

\section{Chave de identificação das espécies de Qualea das cangas da Serra dos Carajás}

1. Pétala branca ou amarela; superfície do fruto não descamante 2.1. Qualea multiflora

1'. Pétala violácea; superfície do fruto descamante. 2.2. Qualea parviflora

2.1. Qualea multiflora Mart., Nov. Gen. Sp. Pl. 1: 134 , t. 80.1826.

Fig. 1c

Árvores, ca. $3 \mathrm{~m}$ alt. Ramos de casca não descamante em placas. Gemas peruladas ovoides. Folhas de filotaxia oposta; estípulas caducas, associadas a glândulas crateriformes; pecíolos $0,4-0,6 \mathrm{~cm}$ compr.; lâminas foliares
8,3-9 × 3,2-3,7 cm, oblongas ou elípticas, glabras na face adaxial, pubescentes na face abaxial; ápice obtuso ou agudo, base obtusa ou arredondada, margem plana. Flores de pétala branca (antes da polinização) ou amarela (depois da polinização). Cápsula elipsoide, superfície não descamante. 


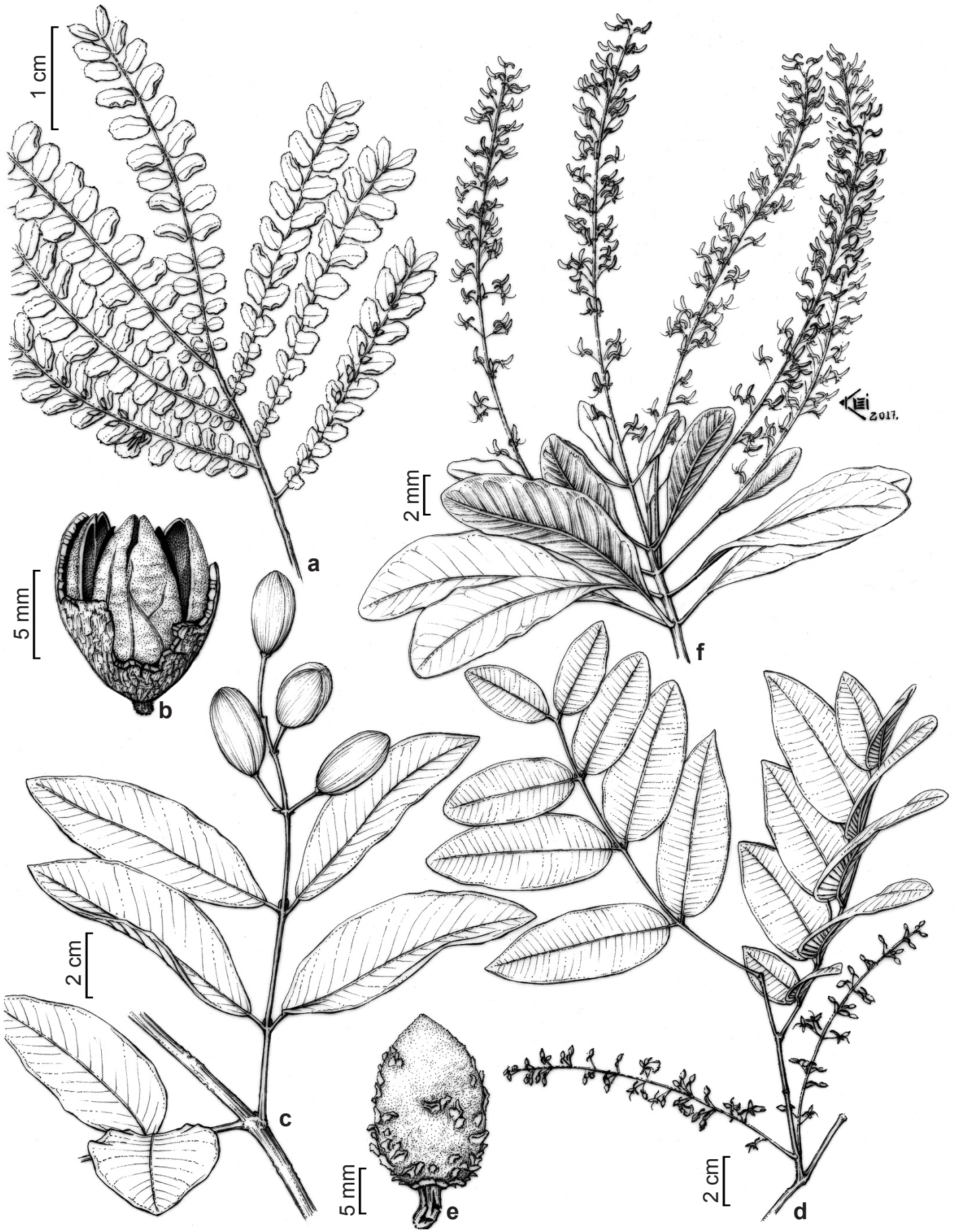

Figura 1 - a-b. Callisthene microphylla - a. ramo com flores; b. fruto. c. Qualea multiflora - ramo com frutos. d-e. Qualea parviflora - d. ramo com flores; e. fruto. f. Vochysia haenkeana - ramo com flores (a. N.A. Rosa et al. 4764; b. P. Cavalcante 2088; c. R.S. Santos \& A.E.S. Rocha 101; d. L.V. Costa et al. 611; e. A.S.L. Silva et al. 1893; f. R.S. Santos \& A.E.S. Rocha 23). Ilustração: Klei Sousa.

Figure 1 - a-b. Callisthene microphylla - a. flowering branch; b. fruit. c. Qualea multiflora - fruiting branch. d-e. Qualea parviflora d. flowering branch; e. fruit. f. Vochysia haenkeana - flowering branch (a. N.A. Rosa et al. 4764; b. P. Cavalcante 2088; c. R.S. Santos \& A.E.S. Rocha 101; d. L.V. Costa et al. 611; e. A.S.L. Silva et al. 1893; f. R.S. Santos \& A.E.S. Rocha 23). Illustration: Klei Sousa. 
Material examinado: Canaã dos Carajás, S11D, 29.VI.2013, fr., R.S. Santos \& A.E.S. Rocha 101 (MG).

Qualea multiflora pode ser separada de $Q$. parviflora, que também ocorre nas áreas de canga, pela pétala branca ou amarela e pelos frutos de superfície não descamante $v s$. pétala violácea e frutos de superfície descamante. Há apenas um registro com frutos em junho. A informação da cor da pétala é baseada em observação pessoal e literatura sobre a espécie (Stafleu 1953).

A espécie é encontrada no norte do Paraguai, leste da Bolívia, leste do Peru e no Brasil (Stafleu 1953). No Brasil é amplamente distribuída nos estados do Amazonas, Bahia, Espírito Santo, Goiás, Maranhão, Mato Grosso, Mato Grosso do Sul, Minas Gerais, Pará, Paraná, Piauí, Rio de Janeiro, Rondônia, Roraima, São Paulo e Tocantins, e no Distrito Federal (Gonçalves et al. 2017). Na Serra dos Carajás foi coletada na Serra Sul: S11D.

2.2. Qualea parviflora Mart., Nov. Gen. Sp. P1. 1: 135, t. 81.1826 .

Fig. 1d-e

Árvores, 2,5-4 m alt. Ramos de casca não descamante em placas. Gemas peruladas ovoides. Folhas de filotaxia oposta, raramente em verticilos 3-meros; estípulas caducas, associadas a glândulas crateriformes; pecíolos 0,3-0,5 cm compr.; lâminas foliares 5,7-8,7 × 2,2-3,3 cm, oblongas ou elípticas, glabras na face adaxial, glabras a glabrescentes na face abaxial; ápice obtuso, emarginado ou agudo, base obtusa ou arredondada, raramente subcordada, margem plana. Inflorescências terminais e subterminais, cincinos 1-3-floros; pedúnculos ausentes; pedicelos 0,4-0,7 cm compr; botões florais 4-6 × 3-4 mm, ápice agudo; cálcar 4-5 mm compr., reto a incurvo; sépala calcarada 9-10 mm compr.; lobos do cálice não calcarados $1-4 \mathrm{~mm}$ compr.; corola com 1 pétala, violácea com linha branca na região central, ca. $6 \times 11 \mathrm{~mm}$, glabra; estame ca. 5 $\mathrm{mm}$ compr., antera ca. $1 \mathrm{~mm}$ compr., glabra, filete ca. 4 mm compr.; estaminódios ausentes; ovário ca. 1,5 × 1,3 mm, densamente hirsuto; estilete ca. $4 \mathrm{~mm}$ compr., glabro; estigma terminal. Cápsula ovoide, superfície descamante.

Material selecionado: Canaã dos Carajás, S11B, 6020'44'S, 50²5'47'W, 753 m, 12.X.2008, fl. e fr., L.V. Costa et al. 611 (BHCB, MG); Parauapebas [Marabá], N4, 19.III.1984, fr., A.S.L. Silva et al. 1893 (MG, NY).

Qualea parviflora é distinta das demais espécies de Vochysiaceae ocorrentes nas áreas de canga da Serra dos Carajás pela pétala violácea e pelos frutos de superfície descamante. Registrada com flores em outubro, e com frutos em março, outubro e dezembro.
Ocorre no leste da Bolívia, norte do Paraguai e Brasil (Stafleu 1953). No Brasil é amplamente distribuída nos estados do Amazonas, Bahia, Ceará, Goiás, Maranhão, Mato Grosso, Mato Grosso do Sul, Minas Gerais, Pará, Pernambuco, Piauí, Rondônia, São Paulo e Tocantins, e no Distrito Federal. Na Serra dos Carajás foi coletada na Serra Norte: N4 e Serra Sul: S11B, em campos rupestres sobre canga.

\section{Vochysia Aubl.}

Vochysia possui cerca de 140 espécies distribuídas na região Neotropical, do sul do México ao sul do Brasil, no estado de Santa Catarina (Stafleu 1948; Vianna \& Martins 2001; Shimizu \& Gonçalves 2015). No Brasil há registro de 88 espécies com ocorrência em florestas tropicais e em formações florestais, savânicas e campestres do cerrado (Flora do Brasil 2020). Há indicação do monofiletismo do gênero e de uma próxima relação com Salvertia A.St.-Hil., gênero monotípico representado por $S$. convallariodora A.St.-Hil., e com ocorrência restrita a áreas de vegetação savânica (Stafleu 1948; Litt 1999; Shimizu 2016). Vochysia apresenta flores amarelas, geralmente com três pétalas, mas poucas espécies apresentam uma única pétala ou flores apétalas (Stafleu 1948). Vochysia pode ser distinguida dos outros dois gêneros que ocorrem na área de estudo pelas folhas não dispostas em râmulos filomórficos e fruto maduro com pericarpo íntegro e região central das valvas fundidas ou apenas levemente afastadas na porção apical (Gonçalves et al. 2017).

3.1. Vochysia haenkeana Mart., Nov. Gen. Sp. Pl. 1: 147 , t. 89.1826.

Figs. 1f; 2c-d

Árvores, 4-20 m alt. Ramos de casca descamante em placas. Gemas não peruladas. Folhas em verticilos 3-meros; estípulas persistentes, não associadas a glândulas; pecíolos $2,3-3 \mathrm{~cm}$ compr.; lâminas foliares 10-12 × 3,6-5 cm, oblongas, glabras; ápice obtuso e retuso, base cuneada, margem plana a ligeiramente revoluta. Inflorescências terminais e axilares, cincinos 1-3-floros; pedúnculos ca. 0,5 cm compr.; pedicelos ca. 0,5 cm compr.; botões florais $0,7-0,9 \times 0,2 \mathrm{~cm}$, ápice arredondado; cálcar 0,7-0,9 cm compr., recurvo; sépala calcarada 1,4-1,5 cm compr.; lobos do cálice não calcarados ca. $1 \mathrm{~mm}$ compr.; corola com 3 pétalas, amarelas, pétala central ca. $6 \times 3$ $\mathrm{mm}$, glabra, pétalas laterais ca. $5 \times 2 \mathrm{~mm}$, glabras; estame ca. $7 \mathrm{~mm}$ compr., antera 4-5 mm compr., glabra, filete 2-3 mm compr.; estaminódios ca. 

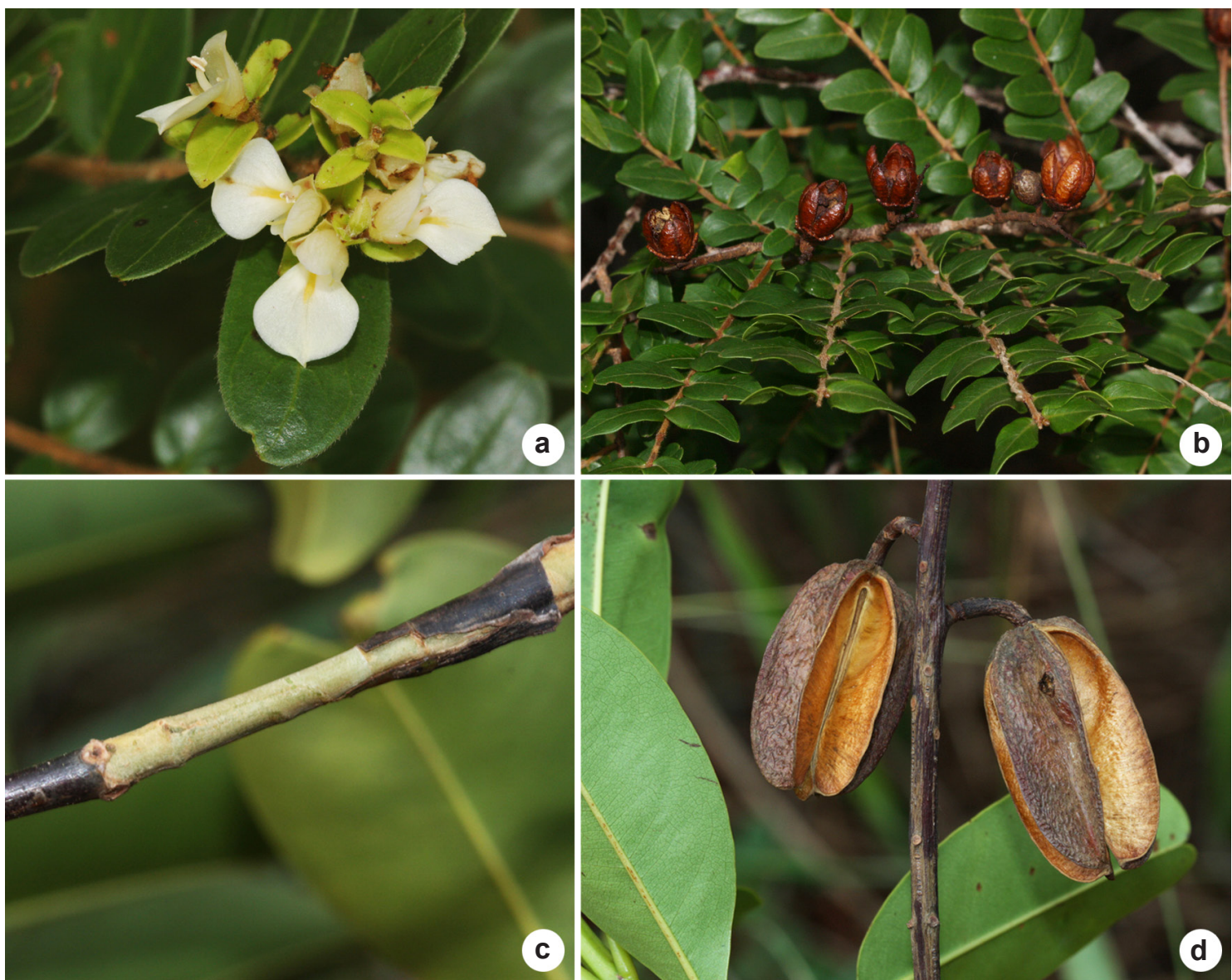

Figura 2 - a-b. Callisthene microphylla - a. detalhe de râmulo com flores; b. ramo com frutos. c-d. Vochysia haenkeana - c. casca do ramo descamante em placas (partes escuras); d. detalhe dos frutos. Fotos: a-d. A.O. Simões. Figure 2 - a-b. Callisthene microphylla - a. detail of flowering branchlet; b. fruiting branch. c-d. Vochysia haenkeana - c. cortex of the branch exfoliant in plates (dark parts); d. detail of the fruits. Photos: a-d. A.O. Simões.

$0,5 \times 0,5 \mathrm{~mm}$, glabros; ovário 1,5-2 $\times 1,5-2 \mathrm{~mm}$, tomentoso; estilete ca. $8 \mathrm{~mm}$ compr., tomentoso na porção basal; estigma terminal. Cápsula oblonga, superfície não descamante.

Material selecionado: Canaã dos Carajás, S11D, 22.VI.2013, fl., R.S. Santos \& A.E.S. Rocha 23 (MG); Parauapebas [Marabá], N1, 3.VI.1986, fl., M.P.M. Lima et al. $111(\mathrm{MG}, \mathrm{RB})$.

Vochysia haenkeana é a única espécie de Vochysiaceae nas áreas de canga da Serra dos Carajás com ramos descamantes em placas e corola 3-mera. Registrada com flores em abril, junho e agosto, e com frutos em agosto.

Apresenta relativa variação morfológica na forma, espessura e brilho das folhas ao longo de sua distribuição, que inclui Bolívia, Brasil e Peru (Stafleu 1948). No Brasil ocorre nos estados do Acre, Amazonas, Goiás, Maranhão, Mato Grosso, Pará, Rondônia e Tocantins, e no Distrito Federal
(Shimizu 2016). Na Serra dos Carajás foi coletada na Serra Norte: N1 e Serra Sul: S11D, em capões florestais e formações rupestres sobre canga.

\section{Agradecimentos}

Aos coordenadores do projeto Flora das Cangas da Serra dos Carajás, Dr. Pedro Lage Viana e Dra. Ana Maria Giulietti, o convite. Ao projeto objeto do convênio MPEG/ITV/ FADESP (01205.000250/2014-10) e ao projeto aprovado pelo CNPq (processo 455505/20144), o financiamento. À Dra. Ana Maria Giulietti e aos dois revisores anônimos, as valiosas sugestões que contribuíram para a finalização do manuscrito. Aos curadores e equipes dos herbários consultados, o acesso aos espécimes. Ao André Olmos Simões pelas fotografias e ao Klei Sousa, as ilustrações. 


\section{Referências}

Bueno OL, Nilson AD \& Magalhães RG (2000) Callisthene inundata nova espécie de Vochysiaceae e primeiro registro desta família no estado do Rio Grande do Sul, Brasil. Iheringia - Séria Botânica 53: 101-116.

França F (1996) O gênero Callisthene Mart. \& Zucc. (Vochysiaceae) no estado da Bahia. Sitientibus 15: 41-47.

Gonçalves DJP, Shimizu GH, Yamamoto K \& Semir J (2017) Vochysiaceae na região do Planalto de Diamantina, Minas Gerais, Brasil. Rodriguésia 68: 159-193.

Kawasaki ML (2007) Vochysiaceae. In: Kubitzki K. The families and genera of vascular plants. Vol. 9. Springer, Berlin. Pp. 480-487.

Litt A (1999) Floral morphology and phylogeny of Vochysiaceae. PhD Dissertation. City University of New York, New York. 264p.

Marcano-Berti L (2005) Vochysiaceae. In: Berry PE, Holst BK \& Yatskievych K. Flora of the Venezuelan Guayana. Vol. 9. Missouri Botanical Garden Press, Saint Louis. Pp. 500-524.

Martins HF (1981) O gênero Callisthene Martius (Vochysiaceae). Ensaio para uma revisão taxinômica. Dissertação de Mestrado. Universidade Federal do Rio de Janeiro, Rio de Janeiro. 115p.

Martins HF (1988) Species novae in Brasilia Vochysiacearum. Bradea 5: 149-151.
Senterre B \& Obiang D (2005) Nouvelles découvertes à propos des Vochysiaceae africaines: Erismadelphus Mildbr. et Korupodendron Litt \& Cheek. Taxonomania 17: 3-18.

Shimizu GH (2016) Phylogenetic, taxonomic and nomenclatural studies in Vochysiaceae and synopsis of Vochysia in Brazil. Tese de Doutorado. Universidade Estadual de Campinas, Campinas. $126 \mathrm{p}$.

Shimizu GH \& Gonçalves DJP (2015) Vochysiaceae. In: Prata AP, Amaral MC, Farias MC \& Alves MV. Flora de Sergipe. Vol. 2. Criação, Aracajú. Pp. 291-294.

Shimizu GH \& Yamamoto K (2012) Vochysiaceae. In: Jacobi CM \& Carmo FF. Diversidade Florística nas Cangas do Quadrilátero Ferrífero. Código, Belo Horizonte. Pp. 209-210.

Shimizu GH, Gonçalves DJP, França F, Simões AO \& Yamamoto K (2016) A remarkable new species of Qualea (Vochysiaceae) from Piauí state, Brazil. Phytotaxa 273: 262-268.

Stafleu FA (1948) A monograph of Vochysiaceae. I. Salvertia and Vochysia. Recueil des Travaux Botaniques Néerlandais 41: 397-540.

Stafleu FA (1952) A monograph of Vochysiaceae. II. Callisthene. Acta Botanica Neerlandica 1: 222-242.

Stafleu FA (1953) A monograph of Vochysiaceae. III. Qualea. Acta Botanica Neerlandica 2: 144-217.

Vianna MC \& Martins HF (2001) Voquisiáceas. In: Reis A. Flora Ilustrada Catarinense. Herbário Barbosa Rodrigues, Itajaí. Pp. 4-33.

\section{Lista de exsicatas}

Arruda AJ 1304 (1.1), 1428 (1.1). Berg CC 517 (1.1). Cardoso A 1953 (1.1). Cavalcante P 2088 (1.1), 2655 (1.1). Costa LV 611 (2.2), 713 (1.1), 1007 (3.1). Daly DC 1718 (1.1). Faria SM 2317 (1.1). Gil A 513 (1.1), 527 (1.1). Harley RM 57342 (1.1), 57390 (1.1). Lima HC 7507 (1.1), 7972 (3.1). Lima MPM 111 (3.1). Lobato LCB 3811 (1.1), 3860 (1.1). Mota NFO 1064 (1.1), 1135 (2.2). Nascimento OC 954 (1.1). Rosa NA 4488 (1.1), 4764 (1.1). Santos RS 23 (3.1), 101 (2.1), 166 (1.1). Secco R 586 (1.1), 639 (1.1). Silva ASL 1829 (1.1), 1893 (2.2). Staudohar GS 30 (1.1). 